\title{
The Influence of Physico-Chemical Parameters to Determine Water Quality: A Review
}

\author{
Azhar Jaffar, Norashikin M. Thamrin, Megat Syahirul Amin Megat Ali, Mohamad Farid Misnan, and \\ Ahmad Ihsan Mohd Yassin
}

\begin{abstract}
Water plays a significant role in domestic, agricultural, fisheries, and many other industries. Unfortunately, with the changes that have taken place in the environment today has contributed a profound impact on the water quality, which furthermore lead to the rise of the new water-based diseases to the human population. To meet the needs of all, the source of the supplied water must be clean and unpolluted. To ensure the quality of the water, the Physico-chemical parameters in the water must be regularly reviewed and tested. The objective of this paper is to review several Physico-chemical factors that can be used to determine the quality of the water and detect the appearance of the contamination agent in that particular water source. The findings and views from a few researchers on these parameters are discussed in this work. From this review, it can be concluded that changes in Physico-chemical parameters such as temperature, pH, salinity, Total Dissolve Solid (TDS), turbidity, Dissolved Oxygen (DO), Biochemical Oxygen Demand (BOD) and Chemical Oxygen Demand (COD) alone cannot be used to determine the quality of the water. These parameters must be stood as the collaborative parameters to have a significant effect on the determination of the water quality.
\end{abstract}

Index Terms - water quality, water quality parameters, freshwater, collaborative parameters, dissolved oxygen.

\section{INTRODUCTION}

Clean and undefiled water is a valuable asset to any country. It contributes to the social and economic development of a country where clean water produces a healthier environment. With only $3.5 \%$ of the world's water being a source of freshwater, it is a valuable asset to a country that has a supply of polluted or less polluted water [1]. The best sources of freshwater are from rivers and lakes.

This manuscript is submitted on $12^{\text {th }}$ May 2020 and accepted on $4^{\text {th }}$ August 2020.Azhar Jaffar is a Doctor of Philosophy candidate at Faculty of Electrical Engineering, Universiti Teknologi MARA (UiTM) Shah Alam Selangor (email: azharfar1977@gmail.com).

Norashikin M. Thamrin, Megat Syahirul Amin Megat Ali and Ahmad Ihsan Mohd Yassin are senior lecturer at Faculty of Electrical Engineering, Universiti Teknologi MARA (UiTM) Shah Alam Selangor (e-mail: norashikin@uitm.edu.my).

Mohamad Farid Misnan is a senior lecturer at Faculty of Electrical Engineering, Universiti Teknologi MARA (UiTM) Pasir Gudang Johor (email: mohamadfarid@uitm.edu.my).

1985-5389/C 2021 The Authors. Published by UiTM Press. This is an open access article under the CC BY-NC-ND license (http://creativecommons.org/ licenses/by-nc-nd/4.0/).
Occasionally there are also underground water sources. Managing rivers pollution is very important as $98 \%$ of the day to day water usage comes from those sources [2].

With the rise of modern technology as well as the industrial revolution, these water sources are becoming increasingly polluted. With the increase in the human population, it has led to the increasing demand for agricultural-based food. It is also aided by the rapid development of rural areas into developed cities, the opening of the plantation area, and the lack of control over land usage [3]. The use of fertilizers and pesticides added to the damage done to the soil that eventually disrupted the natural water ecosystem. These ecological changes will, directly and indirectly, affect the health of the population. Water quality determination nowadays is very important in maintaining the function of the natural ecosystem and the quality of water needed for drinking, industrial and irrigation purposes [4]. Temperature, turbidity, $\mathrm{pH}$, dissolve oxygen and the total amount of solids suspended in water are some important factors that give a big impact on living organisms growth in water bodies [5]. These parameters can be affected by human activities such as agriculture, deforestation, and water use for cooling. The release of high domestic or industrial waste into organic matter into the water results in a significant decline in oxygen concentration and an increase in ammonia and nitrogen concentration, downstream of the effluent input [3]. Water quality in the river or lake can be assessed using a tool called Water Quality Index (WQI) [6]. By using this tool, water quality level measurement can be determined. However, apart from these WQI indices, there are many other scales created by their respective countries to suit the country's climate and season. All of these tools are usually controlled by a body specially appointed to study, implement, and manage water quality problems in the country. Water quality can be evaluated using three main parameters. These parameters are physical, chemical, and biological. Table 1 shows the summarize of all the main groups and parameter variables that can be used to determine the water quality [7].

\section{LITERATURE REVIEW}

Various technical research papers on water quality assessment for different lakes and rivers around the world that 
have been presented or published at the research level is reviewed in this study. Some parameters related to the quality water determination are elaborated. Among these parameters, the water temperature, $\mathrm{pH}$, salinity, Total Dissolve Solid (TDS), turbidity, Dissolved Oxygen (DO), Biochemical Oxygen Demand (BOD) and Chemical Oxygen Demand (COD) are highlighted in this review. When it comes to water pollution, one of the most effective ways to see it is to measure the value of DO contained in water. DO is an important parameter for all aquatic life. Lack of DO indicates that the water is not suitable for aquatic life as well as drinking water, but it is more suitable for other functions such as agriculture and industrial.

TABLE I

PARAMETERS OF WATER QUALITY

\begin{tabular}{llll}
\hline No. & Types of water quality parameters & Chemical parameters & Biological parameters \\
\hline & Physical parameters & $\mathrm{pH}$ & Bacteria \\
\hline 1 & Turbidity & Acidity & Algae \\
\hline 2 & Temperature & Alkalinity & Viruses \\
\hline 3 & Colour & Chloride & Protozoa \\
\hline 4 & Taste and odor & Chlorine residual & \\
\hline 5 & Solids & Sulfate & \\
\hline 6 & Electrical conductivity $(\mathrm{EC})$ & Nitrogen & \\
\hline 7 & & Fluoride & \\
\hline 8 & Iron and manganese & \\
\hline 9 & Copper and zinc & \\
\hline 10 & Hardeness & \\
\hline 11 & Dissolved Oxygen (DO) \\
\hline 12 & Biochemical Oxygen Demand (BOD) & \\
\hline 13 & Chemical Ogygen Demand (COD) & \\
\hline 14 & Toxic inorganic substances \\
\hline 15 & Toxic organic substances \\
\hline 16 & Radioactive substances \\
\hline
\end{tabular}

Qin Ren, Long Zhang, Yaoguang Wei, and Daoliang Li A [8] has introduced a method for predicting dissolved oxygen in aquaculture water in an aquaponics system. Their experiment data has been collected from the aquaponics system in the greenhouse of the Shougang experimental base in Shandong. A standard parameter like temperature, $\mathrm{pH}$ value, conductivity, dissolved oxygen, and a few other parameters are tested. They found out that the environmental factor influences the DO. In addition to that, the correlation coefficients of $\mathrm{pH}$, humidity, and temperature are strongly correlated to DO. The estimation technique that has been used by them provided high prediction accuracy and strong generalizability which fits the environmental factors and DO relationships.

Senlin Zhu and Salim Heddam in [9] used two mathematical modeling approaches to predict daily dissolve oxygen solutions at Three Gorges Reservoir, China. They have developed systems based on non-linear techniques namely extreme learning machine (ELM) and multilayer perceptron neural network (MLPNN). Water quality data from four rivers flowing into the Three Gorges Reservoir zone, China. They choose to observe several parameters for the study. The selected water quality data include water temperature, $\mathrm{pH}$, permanganate index, nitrogen ammonia, electrical conductivity, chemical oxygen demand, nitrogen volume, phosphorus volume, and even DO. The accuracy of the ELM model is then compared with the MLPNN standard using several error statistic techniques. The results show that the ELM and MLPNN models work well for others but some decisions do not meet the specifications required. According to the authors, the results obtained are based on the level of pollution in each river. They also found that the MLPNN model had better results in testing DO levels than the ELM model. The authors conclude that the ELM and MLPNN models can be used to make predictions of DO at low levels of contamination but are not suitable for rivers with high levels of pollution.

Ehsan Olyaie, Hamid Zare Abyaneh and Ali Danandeh Mehr [10] studied three different methods: (1) two types of artificial neural network (ANN) namely multi-linear perceptron (MLP) and radial-based function (RBF); (2) the advancement of genetic programming that is linear genetic programming (LGP); and (3) support vector machine (SVM) techniques. Most water quality models that have been developed and used previously in dissolved oxygen (DO) predictions are rather complex. Besides, the existing and reliable data for the new DO development and calibration process are rather limited. Therefore, there is a need to study and develop models that can handle these water parameters, and so that the DO can be easily estimated at any desired river test site, where testing can be done in the short term. Few DO prediction models were tested at Delaware River, Trenton, United States. To successfully test 
the DO value, several input parameters consisting of $\mathrm{pH}$, electrical conductivity (EC), temperature (T), and river discharge (Q) were used. These models use the statistical properties of a data series with a certain number of input variables. From the results obtained by the ANNs, LGP, and SVM models, it is somewhat counterintuitive. Interestingly, a certain parameter is higher in the SVM models than those in ANNs and LGP models. Despite that, some are lower. The results have also demonstrated that ANNs, LGP, and SVM give a good estimation accuracy for low values of DO but cannot maintain their accuracy for a higher value of DO. In summary, the analysis presented in their study shows that the SVM method is better compared to both the ANN model and the LGP model in predicting DO levels in the water.

Novita Ayu Dewanti and Agus Maman Abadi [11] used the fuzzy logic system in their field of study to classify the water quality status of the Gajahwong River. The Gajahwong River is one of the largest rivers in Yogyakarta, Indonesia and it flows in the heart of Yogyakarta city. In their study, 11 parameters, which were consisting of chemical, biological and physical parameters used to classify water quality status, namely, DO, $\mathrm{COD}$, temperature, $\mathrm{pH}, \mathrm{BOD}$, demand for chlorine, lead, nitrite, nitrate, Escherichia coli, oil, and fat. Three different stations were used in the period from 2007 to 2017 in the Gajahwong River using these parameters to assess the quality of the water there. The fuzzy logic technique begins with the use of these parameters as inputs, with Mamdani's method as a fuzzy suitability system. The Mamdani system is often used in fuzzy logic because they are designed to convey all knowledge contained in the form of IF-THEN rules expressed in natural languages [12]. For comparison, these researchers used data obtained from the Yogyakarta Special Region Environmental Agency website. The results of the classification of water quality status obtained from the site have been compared with the results of the Mamdani fuzzy logic system defuzzification of centroid and the defuzzification of the largest of maximum (LOM). Overall, they found that the use of fuzzy logic can be used to assess the quality of the Gajahwong River water quality application. They also found that the Mamdani method with the LOM defuzzification gave $96.97 \%$ accuracy while the Mamdani method with the Centroid defuzzification gave $90.90 \%$ accuracy. This shows that the Mamdani method with LOM defuzzification provides higher accuracy than the Mamdani method with the Centroid defuzzification.

Juliana Tais Engelmann, Rejane Frozza, Adilson Ben da Costa, and Rodrigo Augusto Klamt [13] have also used fuzzy techniques to develop systems that capable of assessing the water quality. The systems receive data as an indicator of water quality and then determine its classification by a calculated score using a scale of $0-100$. To determine water quality, the authors used several parameters such as turbidity, $\mathrm{pH}$, fluoride, chlorine-free residue, colour, and coliform volume. They implemented the computer graphic application called InFuzzy software as the fuzzy logic application, which was not used by [11]. In their work, they used the discrete, trapezoidal, and ramp functions to the right techniques, Mamdani's inference and defuzzification method using Centroid. The computer graphic application was used to obtain the output information.
Using InFuzzy, quantitative, and qualitative bibliometric analysis data were performed. The quantitative analysis produces statistics that show data while qualitative analysis focuses on analyzing social reality. It is found that the quality of the water can be evaluated satisfactorily using a set of parameters collected through fuzzy logic applications. The set parameters are coliform, fluoride, chlorine-free residue, $\mathrm{pH}$, turbidity, and colour. It also shows that the use of diffuse logic to evaluate urban water quality is also an effective method.

The comparative study of techniques between different types of testing based on Water Quality Indices (WQIs) also presented by Ioanna Zotou et. al. [14]. They conducted a study to test the water quality in Polyphytos artificial lake, a manmade Mediterranean lake. Several previous studies over the last decade have focused on comparative evaluation studies between different WQIs. This has attracted the attention of many parties where although there are various types of WQI available, none are available globally accepted. Therefore, studies on the effectiveness of these different WQIs are important to do comparatively based on different environments. This ensures that while using the large number of WQIs, they respond almost equal and can thus be used to facilitate the most appropriate recommendations. The study was conducted based on the monthly water quality index for one year obtained by the sampling method. The several WQIs used were the Prati's Index of Pollution, Bhargava's Index, Oregon WQI, Dinius' Second Index, and the Weighted Arithmetic WQI. Also, they used the results from previous research using the National Sanitation Foundation WQI (NSFWQI) and the Canadian Council of Ministers of Environment WQI (CCME-WQI) for the comparative study of the same dataset. The Physico-chemical parameters such as temperature, DO, pH, EC, turbidity, BOD, COD, suspended solids (TSS), nitrogen, ammonia nitrogen, Kjeldahl nitrogen (TKN) and phosphorus were taken from June 2004 to May 2005 in their work. To summarize, the tests show differences in the classification of the water quality based on a different methodology. This difference is due to the use of different techniques. Factors such as the number of parameters used and the combination of water quality parameters included in each index provide varying results. Methods of using mathematical formulas to calculate sub-index scores of individual parameters while changing the concentration also gives a different outcome [14]. From several WQIs index that has been tested, Bhargava's WQI has categories Polyphytos man-made lakes into 3rd WQIs quality class for satisfactory water quality while other WQIs place Polyphytos man-made lakes in the lower category, expressing bad quality conditions. WQIs not only simplify the entire assessment process by providing a specific calculation framework and minimizing the information needed for quality interpretation, but it also simplifies the communication process by providing clear and easy-to-manage results from decision-makers and the public.

Shannon entropy as a tool for assessing water quality was used [15]. The study was conducted in the Beki river, Assam of the Indian state. To optimize the design of the water treatment system in increasing the water quality at the drinking water level, Entropy weights were used to develop the 
weighted water quality index (EWQI). To determine the appropriate test center area along the Beki River, The MultiCritical Decision-Making Approach to Priority Order by the Similarity to Ideal Solution (TOPSIS) was used. It is used to test the water quality associated with the irrigation standards as the main criteria. The temperature, $\mathrm{pH}, \mathrm{DO}, \mathrm{BOD}$, Total suspended solids (TSS), Total dissolved solids (TDS), Total hardness (TH), Sodium, Chloride, and several other chemical and biology parameters were used to determine the water quality. The water quality classification scale used by them is based on the EWQI standard. Table 2 shows the water quality classifications according to EWQI standard [16].

TABLE II

EWQI GROUND WATER QUALITY CLASSIFICATION

\begin{tabular}{cc}
\hline Range & Quality Level \\
\hline$<50$ & Excellent water quality \\
\hline 50 to 100 & Good water quality \\
\hline 100 to 150 & Moderate water quality \\
\hline 150 to 200 & Poor water quality \\
\hline$>200$ & Very Poor water quality \\
\hline
\end{tabular}

It was found that, using EWQI technique, the quality of Beki river water is between excellent to poor and ranged from 29.3 to 150.6 using EWQI classification. This result was influenced by several factors derived from a source of static studies showing that the Beki river was contaminated by the disposal of domestic wastewater that caused it to be contaminated. Statistics show that there are several test centers along the river that provide poor statistical readings that contribute to the major causes of pollution. This study provides a comprehensive assessment of water quality that begins with the introduction of resources to make decisions water quality suitability for use. Contrarily, it provides a strong and comprehensive basis compared to conservative water quality management.

\section{WATER PARAMETERS}

This section explains the water parameters used in the water quality assessment as it can be easily affected physically, which is reflected in the physical changes that occur to the water. It also can be tested based on chemical changes. On top of that, they can be directly measured using modern sensor technologies. Using electronic sensors, several parameters such as turbidity, temperature, $\mathrm{pH}$, and dissolved oxygen can be promptly measured at the site. While on the other hand, the chemical changes in the water body such as BOD and COD, can be estimated through laboratory works.

\section{A. Dissolved Oxygen}

Dissolved oxygen (DO) is an important element to be known in water content. It can determine the level of water contamination based on the lack of oxygen in the water and also can indicate the increased use of oxygen by organic substances in the water [7]. The higher the DO value the better the quality of the water. On the other hand, the lower the value of DO obtained then the lower the water quality will be [17]. Temperature plays an important role in determining the DO in the water. The amount of oxygen that the water can hold depends on the temperature of the salinity and the water flow pressure [18].

\section{B. Temperature}

Temperature changes affect the chemical, biological and physical parameters of surface water [18]. These changes affect the dissolved oxygen levels in the water and photosynthesis of aquatic plants and several other problems [19]. The absorption rate of oxygen and other gases decreases with the increasing water temperature [20]. The river's temperature will not change rapidly due to variations in temperature in the air caused by the thermal inertia, which is depending on the current state of the river's hydrology [21]. Therefore, the appropriate time delay should be considered in the effect of air temperature to determine the effective rate of water temperature change.

\section{Water $p H$}

$\mathrm{pH}$ is an important element to detect toxicity in aqueous solutions. In chemistry, $\mathrm{pH}$ ranges from 0 to 14 . It indicates the acidity or alkalinity of that water solution. The value of drinking water is to have a $\mathrm{pH}$ level of 7. If the $\mathrm{pH}$ value is less than 7 and moving towards 0 , it indicates an increased level of acidity. Whereas the $\mathrm{pH}$ value exceeds the value of 7 and rises to 14 , this indicates an increase in alkaline levels in water [22]. Acidic conditions occur when water contains more free hydrogen ions and the increase in alkalinity is due to the reduction in photosynthetic activity, carbon dioxide assimilation and bicarbonate [18]. The $\mathrm{pH}$ of water determines the amount of solute that can be dissolved in the water [15], [23]. It also determines the biological availability that can be utilized by aquatic life for nutrients such as nitrogen or carbon and heavy metals such as copper, cadmium, etc.

\section{Total Dissolve Solid}

Total Dissolved Solids (TDS) is a measurement of the combined content of inorganic and organic matter or salts found in water [24]. These inorganic materials are usually composed of cations such as calcium, magnesium, potassium, and sodium while the anions are carbonates, nitrates, bicarbonates, chlorides, and sulfates. TDS means that the water is not pure and solid by itself because it contains other material in it [25]. TDS usually correlates and affect $\mathrm{pH}$ reading. The presence of dissolved solids in the water will affect the taste of the water [22]. Therefore, TDS cannot have a significant deviation of its levels from standard value in water. Not only it is not acceptable to consumers because of taste but also due to other effects. This condition may states that a possible bacterial contamination in lower a TDS waters and it is also very harmful to human health [26]. 


\section{E. Turbidity}

Turbidity is the cloudiness of the effects caused by various individual particles. These particles are generally invisible to the naked eye, just like what happens to smoke in the air. Turbidity results in a decrease in the intensity of light that passes through cloudiness or turbidity water due to light, absorption, and reflection of light. Technically, turbidity can be defined as a disorder or fluid disturbance caused by suspended solids that are usually not visible to the naked eye [27]. It only describes a substance that is in the water. Water usually contains suspended solids that are made up of various particles. Some large, heavy particles reach the bottom of the river. These are called settleable solids. The tiny particles are just settling down slowly before they settle to the water's bottom [28]. Turbidity can affect the growth rate of algae and other microaquatic plants in the water. Increased turbidity can lead to a decrease in aquatic plant growth due to a decrease in the amount of light for plants to perform photosynthesis. Turbidity is also able to increase the water temperature because the particles in the water to the surface absorb more heat. These factors lead to the reduction of dissolved oxygen [29]. Turbidity measurement is an important test when trying to determine water quality. In drinking water, the higher the turbidity level, then it is easier for a person to get water-related illnesses [30].

\section{F. Biological Oxygen Demand (BOD)}

Biological Oxygen Demand (BOD) is an important process that occurs in the water due to biological organisms in the water solution. BOD represents the amount of oxygen used during the process of aerobic decomposition of organic matter caused by microorganisms [31]. The amount of dissolved oxygen required by biological organisms during aerobic processes to break down the organic matter present in a particular water sample at a certain temperature over a certain period. BOD is one of the common measurement systems to measure the rate of organic matter that pollutes water. This means that the smaller pollution in the water, the greater the oxygen content in the water [32].

\section{G. Chemical Oxygen Demand (COD)}

Chemical Oxygen demand (COD) is a test performed to determine the rate of oxygen consumption in water for the process of oxidizing a solution that can dissolve in water and also oxidizing the particles or combinations of more than one particle called particulate. Apart from BOD, COD is a very important water quality parameter. Like the BOD parameter, COD can provide an index to see the effects of discharges on the environment [33]. Higher COD index values mean more organic matter oxidation in the sample being made. This will reduce the level of dissolved oxygen (DO) in the sample. Lack of DO in water can cause anaerobic conditions that damage higher forms of aquatic life. Compared to BOD tests that take up to 5 days or more, COD tests take between 2 and 3 hours [31],[34]. COD testing is often used as a substitute for BOD testing due to shorter test periods.

\section{CONCLUSION}

Water quality reflects the relationship of all hydrological properties including the physical, chemical, and biological properties of water bodies. Therefore, water quality assessment involves the analysis of physiological, biological, and microbiological parameters that reflect the biotic and abiotic ecosystem status. Temperature, turbidity, nutrients, hardness, alkalinity, and dissolved oxygen are part of the Physicochemical parameters that play an important role in the growth of living organisms in the body of water. Thus, from this review it can be seen that researchers have shown that Temperature, $\mathrm{pH}$, TDS, DO, BOD, COD, EC, etc are essential parameters used for water quality testing, analysis, indexing and modeling purpose and considered individually for analysis of reservoir, river, stream water quality.

Water quality monitoring is very effective in determining the current status of hydrological conditions for water and water pollution as well as the long-term safety of polluted water. Regular water monitoring will help in taking long-term precautions, which will help protect water quality and protect human health.

\section{REFERENCES}

[13] J. T. Engelmann, R. Frozza, A. Ben da Costa, and R. A. Klamt, "Sfaquali - fuzzy system for urban water quality assessment," Water Pract. Technol., vol. 14, no. 3, pp. 625-632, 2019. 
[14] I. Zotou, V. A. Tsihrintzis, and G. D. Gikas, "Water quality evaluation of a lacustrine water body in the Mediterranean based on different water quality index (WQI) methodologies," J. Environ. Sci. Heal. - Part A Toxic/Hazardous Subst. Environ. Eng., vol. 0, no. 0, pp. 1-12, 2020.

[15] K. Raghvendra, S. Rahul, D. Ajay, and S. K. Bimlesh, "Information entropy as a tool in surface water quality assessment," Environ. Earth Sci., vol. 0, no. 0, p. 0, 2019.

[16] J. Chen, Q. Huang, Y. Lin, Y. Fang, H. Qian, and R. Liu, "Hydrogeochemical Characteristics and Quality Assessment of Groundwater in an Irrigated Region ,"pp. 1-18, 2019.

[17] M. Arief, "Development of Dissolved Oxygen Concentration Extraction Model Using Landsat Data Case Study: Ringgung Coastal Waters," Int. J. Remote Sens. Earth Sci., vol. 12, no. 1, p. 1, 2017.

[18] V. S. Kale, "Consequence of Temperature , $\mathrm{pH}$, Turbidity and Dissolved Oxygen Water Quality Parameters.," Int. Adv. Res. J. Sci. Eng. Technol. ISO, vol. 3, no. 8, pp. 186-190, 2016.

[19] W. Bi et al., "Evolution characteristics of surface water quality due to climate change and LUCC under scenario simulations: A case study in the Luanhe River Basin," Int. J. Environ. Res. Public Health, vol. 15 , no. $8,2018$.

[20] L. Zlatanovic, A. Moerman, J. P. van der Hoek, J. Vreeburg, and M. Blokker, "Development and validation of a drinking water temperature model in domestic drinking water supply systems," Urban Water J., vol. 14, no. 10, pp. 1031-1037, 2017.

[21] S. Zhu, E. K. Nyarko, and M. Hadzima-Nyarko, "Modelling daily water temperature from air temperature for the Missouri River," PeerJ, vol. 2018, no. 6, pp. 1-19, 2018.

[22] R. Islam et al., "Assessment of $\mathrm{pH}$ and Total Dissolved Substances (TDS) in the Commercially Available Bottled Drinking Water," IOSR J. Nurs. Heal. Sci. Ver. IX, vol. 6, no. 5, pp. 35-40, 2017.

[23] Y. Zhang et al., "PH Effect on Heavy Metal Release from a Polluted Sediment," J. Chem., vol. 2018, 2018.

[24] M. Rafiqul Islam, "A Study on the TDS Level of Drinking Mineral Water in Bangladesh," Am. J. Appl. Chem., vol. 4, no. 5, p. 164, 2016.

[25] S. Choo -in, "the Relationship Between the Total Dissolved Solids and the Conductivity Value of Drinking Water, Surface Water and Wastewater," 2019 Int. Acad. Res. Conf. Amsterdam, pp. 11-16, 2019.

[26] M. S. Islam, “An Assessment on Different Solids, Dissolved Oxygen in Industrial Effluents and Its Impact on Public Health," Am. J. Biomed. Sci. Res., vol. 5, no. 5, pp. 382-390, 2019.

[27] B. G. B. Kitchener, J. Wainwright, and A. J. Parsons, "A review of the principles of turbidity measurement," Prog. Phys. Geogr., vol. 41, no. 5, pp. 620-642, 2017.

[28] A. Azis, H. Yusuf, Z. Faisal, and M. Suradi, "Water turbidity impact on discharge decrease of groundwater recharge in recharge reservoir," Procedia Eng., vol. 125, pp. 199-206, 2015.

[29] T. Léziart, P. M. Dutheil de la Rochere, R. Cheswick, P. Jarvis, and A. Nocker, "Effect of turbidity on water disinfection by chlorination with the emphasis on humic acids and chalk," Environ. Technol. (United Kingdom), vol. 40, no. 13, pp. 1734-1743, 2019.

[30] A. Soros, J. E. Amburgey, C. E. Stauber, M. D. Sobsey, and L. M. Casanova, "Turbidity reduction in drinking water by coagulationflocculation with chitosan polymers," J. Water Health, vol. 17, no. 2, pp. 204-218, 2019.

[31] G. Tintometer, "The Importance of Biochemical Oxygen Demand (BOD) in the Water Analysis Sector," Aet, no. May, pp. 12-13, 2015.

[32] S. Ihsan Wira and S. Sunarsih, "Facultative Stabilization Pond: Measuring Biological Oxygen Demand using Mathematical Approaches," E3S Web Conf., vol. 31, pp. 1-4, 2018.

[33] J. Li, G. Luo, L. J. He, J. Xu, and J. Lyu, "Analytical Approaches for Determining Chemical Oxygen Demand in Water Bodies: A Review," Crit. Rev. Anal. Chem., vol. 48, no. 1, pp. 47-65, 2018.

[34] P. A. G. Ghalimath, "An Overview of Phenomenon of BOD and COD,” Int. Res. J. Eng. Technol., vol. 4, no. 8, pp. 264-266, 2017. 